\title{
Avelumab monotherapy as first-line or second-line treatment in patients with metastatic renal cell carcinoma: phase lb results from the JAVELIN Solid Tumor trial
}

Ulka Vaishampayan ${ }^{1 *}$, Patrick Schöffski ${ }^{2}$, Alain Ravaud ${ }^{3}$, Christian Borel ${ }^{4}$, Julio Peguero ${ }^{5}$, Jorge Chaves ${ }^{6}$, John C. Morris ${ }^{7}$, Nuria Kotecki ${ }^{8}$, Martin Smakal ${ }^{9}$, Dongli Zhou ${ }^{10}$, Silke Guenther ${ }^{11}$, Marcis Bajars ${ }^{12}$ and James L. Gulley ${ }^{13}$

\begin{abstract}
Background: Antibodies targeting programmed death-1 (PD-1) or programmed death-ligand 1 (PD-L1) have shown clinical activity in the treatment of metastatic renal cell carcinoma (mRCC). This phase lb cohort of the JAVELIN Solid Tumor trial assessed the efficacy and safety of avelumab (anti-PD-L1) monotherapy in patients with mRCC as either first-line $(1 \mathrm{~L})$ or second-line $(2 \mathrm{~L})$ treatment.

Methods: Patients with mRCC with a clear-cell component who were treatment naive ( $1 \mathrm{~L}$ subgroup) or had disease progression after one prior line of therapy ( $2 \mathrm{~L}$ subgroup) received avelumab $10 \mathrm{mg} / \mathrm{kg}$ intravenous infusion every 2 weeks. Endpoints included confirmed best overall response, duration of response (DOR), progression-free survival (PFS), overall survival (OS), PD-L1 expression, and safety.
\end{abstract}

Results: A total of 62 patients were enrolled in the $1 \mathrm{~L}$ subgroup, and 20 patients were enrolled in the $2 \mathrm{~L}$ subgroup. In the $1 \mathrm{~L}$ and $2 \mathrm{~L}$ subgroups, confirmed objective response rates were 16.1 and 10.0\%, median DOR was 9.9 months (95\% confidence interval [Cl], 2.8-not evaluable) and not evaluable (95\% Cl, 6.9-not evaluable), median PFS was 8.3 months ( $95 \% \mathrm{Cl}, 5.5-9.5)$ and 5.6 months ( $95 \% \mathrm{Cl}, 2.3-9.6)$, and median OS was not evaluable (95\% Cl, not evaluable) and 16.9 months ( $95 \%$ Cl, 8.3-not evaluable), respectively. Treatment-related adverse events (TRAEs) of any grade occurred in 51 patients in the $1 \mathrm{~L}$ subgroup (82.3\%) and 14 patients in the $2 \mathrm{~L}$ subgroup (70.0\%). Grade $\geq 3$ TRAEs occurred in eight patients in the $1 \mathrm{~L}$ subgroup (12.9\%) and one patient in the $2 \mathrm{~L}$ subgroup (5.0\%). No treatment-related deaths occurred. Conclusion: Avelumab showed clinical activity and a manageable safety profile in both the $1 \mathrm{~L}$ and $2 \mathrm{~L}$ treatment setting in patients with mRCC. These data support the use of avelumab in combination with other agents in mRCC.

Trial registration: ClinicalTrials.gov: NCT01772004; registered 21 January, 2013.

Keywords: Avelumab, PD-L1, Renal cell carcinoma, Metastatic, Phase I

\footnotetext{
* Correspondence: vaishamu@karmanos.org

'Karmanos Cancer Institute, Wayne State University, 4100 John R. Street,

Detroit, Ml 48201, USA

Full list of author information is available at the end of the article
}

(c) The Author(s). 2019 Open Access This article is distributed under the terms of the Creative Commons Attribution 4.0 International License (http://creativecommons.org/licenses/by/4.0/), which permits unrestricted use, distribution, and reproduction in any medium, provided you give appropriate credit to the original author(s) and the source, provide a link to the Creative Commons license, and indicate if changes were made. The Creative Commons Public Domain Dedication waiver (http://creativecommons.org/publicdomain/zero/1.0/) applies to the data made available in this article, unless otherwise stated. 


\section{Background}

Renal cell carcinoma (RCC) is the most common type of kidney cancer, with clear-cell RCC being the most common subtype [1]. Historically, metastatic RCC (mRCC) has had a poor prognosis, with an average 5-year survival rate of $\approx 11 \%$ [2]. Also, mRCC is highly resistant to chemotherapy and radiation treatment $[3,4]$. In recent years, progress has been made in the treatment of advanced or metastatic RCC and multiple targeted therapies have been approved, including tyrosine kinase inhibitors (TKIs), mammalian target of rapamycin inhibitors), and the antivascular endothelial growth factor antibody bevacizumab in combination with interferon alpha [5]. These targeted therapies have shown clinical activity and prolonged survival in patients with $\mathrm{mRCC}[6]$; however, responses are generally short-lived, development of treatment resistance is common [5, 7], and different classes of targeted therapy are associated with characteristic toxicity profiles that have implications for patient treatment selection [5].

In recent years, immune checkpoint inhibitors (ICIs) have become an established therapeutic class, with clinical activity seen in various tumor types [8, 9]. In RCC, the immune checkpoint protein programmed death-1 (PD-1) and its ligand (PD-L1) are widely expressed on immune cells that infiltrate the tumor microenvironment and tumor cells, respectively [10-12]. Moreover, increased PD-1/L1 expression in RCC is associated with aggressive pathological features and a worse prognosis [10-12]. In patients with mRCC, anti-PD-1 and antiPD-L1 antibodies have shown promising responses and improved overall survival (OS), both as monotherapy and in combination with other classes of agents. Nivolumab (anti-PD-1) was the first agent in this class to be approved by regulatory authorities, based on findings from the randomized phase III CheckMate 025 trial, which compared nivolumab monotherapy with everolimus in patients with advanced RCC who had received prior antiangiogenic therapy [13]. More recently, nivolumab in combination with ipilimumab (anti-cytotoxic T-lymphocyte protein 4) was approved for patients with previously untreated, intermediate- or poor-risk, advanced RCC, based on OS data from the phase III CheckMate 214 trial of nivolumab plus ipilimumab compared with sunitinib [14].

Avelumab is a human IgG1 monoclonal antibody that binds PD-L1, inhibiting the interaction with PD-1 and restoring antitumor immune responses [15]. Avelumab has been approved in various countries for the treatment of metastatic Merkel cell carcinoma and advanced urothelial carcinoma that has progressed following platinum-containing therapy [16]. The large, phase I, multicohort JAVELIN Solid Tumor trial (>1700 patients; NCT01772004) assessed avelumab monotherapy in various tumors [17-23]. Here we report the efficacy and safety data from the phase Ib cohort of patients with mRCC, including subgroups who received either firstline $(1 \mathrm{~L})$ or second-line $(2 \mathrm{~L})$ avelumab monotherapy. When this study was initiated, phase III data for an ICI (nivolumab) as a $2 \mathrm{~L}$ treatment for advanced RCC had been reported [13]; however, no data for $1 \mathrm{~L}$ ICI treatment had been reported, providing the rationale to investigate the clinical activity of avelumab in both the $1 \mathrm{~L}$ and $2 \mathrm{~L}$ treatment settings. Subsequently, studies of anti-PD-1/PD-L1 antibodies in combination with targeted therapies as $1 \mathrm{~L}$ treatment for advanced or metastatic RCC were reported [14, 24-27]; this includes trials of avelumab combined with axitinib, particularly the recently reported phase III JAVELIN Renal 101 study, which showed superior efficacy with this regimen compared with sunitinib, and led to the recent FDA approval of avelumab and axitinib in combination for the treatment of advanced RCC [16, 25, 26]. Pembrolizumab (anti-PD-1) in combination with axitinib has also been approved by the FDA [24]. By evaluating the activity of avelumab monotherapy, the current study provides context for the improved efficacy seen with avelumab plus axitinib.

\section{Methods}

\section{Study design and patients}

JAVELIN Solid Tumor is an international, multicohort, open-label, phase I trial. Key eligibility criteria for this phase Ib expansion cohort were adults with histologically or cytologically confirmed mRCC with a clear-cell component, an Eastern Cooperative Group performance status (ECOG PS) of 0 or 1 and measurable disease by Response Evaluation Criteria in Solid Tumors (RECIST) v1.1. Patients were enrolled irrespective of PD-L1 expression status and had received no prior treatment $(1 \mathrm{~L}$ subgroup) or had disease progression after one prior line of metastatic therapy (2 L subgroup). Key exclusion criteria included prior treatment with a T-cell-targeting antibody/drug; other cancer diagnosis within 5 years prior to study entry; and known autoimmune disease or hypersensitivity to monoclonal antibodies. Full eligibility criteria have been reported [17].

The trial was conducted in accordance with the Declaration of Helsinki and the International Council for Harmonisation Guideline for Good Clinical Practice. The protocol was approved by the institutional review board or independent ethics committee of each centre; all patients provided written informed consent before enrolment.

\section{Treatment}

All patients received avelumab $10 \mathrm{mg} / \mathrm{kg}$ by intravenous infusion every 2 weeks until disease progression, unacceptable toxicity, or other criteria for withdrawal were 
Table 1 Patient baseline characteristics

\begin{tabular}{|c|c|c|}
\hline Characteristics & $\begin{array}{l}1 \mathrm{~L} \\
(n=62)\end{array}$ & $\begin{array}{l}2 \mathrm{~L} \\
(n=20)\end{array}$ \\
\hline \multicolumn{3}{|l|}{ Age, $n(\%)$} \\
\hline$<65$ years & $37(59.7)$ & $7(35.0)$ \\
\hline$\geq 65$ years & $25(40.3)$ & $13(65.0)$ \\
\hline Median age (range), years & $62(36-85)$ & $69(30-80)$ \\
\hline \multicolumn{3}{|l|}{ Sex, $n(\%)$} \\
\hline Male & $43(69.4)$ & $15(75.0)$ \\
\hline Female & 19 (30.6) & $5(25.0)$ \\
\hline \multicolumn{3}{|l|}{ ECOG PS, $n(\%)$} \\
\hline 0 & $37(59.7)$ & $9(45.0)$ \\
\hline 1 & $25(40.3)$ & $11(55.0)$ \\
\hline \multicolumn{3}{|l|}{ MSKCC prognostic risk group, $n(\%)$} \\
\hline Favorable & $2(3.2)$ & 0 \\
\hline Intermediate & $53(85.5)$ & $17(85.0)$ \\
\hline Poor & $7(11.3)$ & $3(15.0)$ \\
\hline \multicolumn{3}{|l|}{ IMDC prognostic risk group, $n(\%)$} \\
\hline Favorable & $24(38.7)$ & $5(25.0)$ \\
\hline Intermediate & $27(43.5)$ & $13(65.0)$ \\
\hline Poor & $11(17.7)$ & $2(10.0)$ \\
\hline $\begin{array}{l}\text { Median time since diagnosis of } \\
\text { metastatic disease (range), months }\end{array}$ & $2.5(0.4-90.4)$ & $\begin{array}{l}15.0 \\
(1.6-80.4)\end{array}$ \\
\hline \multicolumn{3}{|c|}{$\begin{array}{l}\text { Number of prior anticancer therapy lines for } \\
\text { metastatic or locally } \\
\text { advanced disease, } n(\%)\end{array}$} \\
\hline 0 & $62(100.0)^{a}$ & 0 \\
\hline 1 & 0 & $19(95.0)$ \\
\hline 2 & 0 & 0 \\
\hline 3 & 0 & 0 \\
\hline$\geq 4$ & 0 & $1(5.0)$ \\
\hline \multicolumn{3}{|l|}{ PD-L1 status ( $\geq 1 \%$ tumor cells), $n$ (\%) } \\
\hline Positive & $20(32.3)$ & $4(20.0)$ \\
\hline Negative & 21 (33.9) & $9(45.0)$ \\
\hline Not evaluable & 21 (33.9) & $7(35.0)$ \\
\hline
\end{tabular}

a One patient (1.6\%) received prior adjuvant therapy

$1 L$ first-line subgroup, $2 L$ second-line subgroup, ECOG PS Eastern Cooperative Oncology Group performance status, MSKCC Memorial Sloan-Kettering Cancer Center, IMDC International Metastatic Renal Cell Carcinoma Database Consortium, $P D-L 1$ programmed death-ligand 1

met (reported previously) [17]. Dose reductions were not permitted. Antihistamine premedication was given 30-60 min before each infusion. Grade 2 AEs were managed by treatment delays of up to two subsequent omitted doses; events that did not resolve to grade $\leq 1$ or recurred resulted in permanent treatment discontinuation.

\section{Assessments}

Clinical activity and safety were analyzed in all patients who received at least one dose of avelumab. Tumors
Table 2 Confirmed objective responses

\begin{tabular}{|c|c|c|}
\hline Response & $\begin{array}{l}1 \mathrm{~L} \\
(n=62)\end{array}$ & $\begin{array}{l}2 \mathrm{~L} \\
(n=20)\end{array}$ \\
\hline \multicolumn{3}{|l|}{ Best overall response, $n(\%)$} \\
\hline Complete response & $1(1.6)$ & 0 \\
\hline Partial response & $9(14.5)$ & $2(10.0)$ \\
\hline Stable disease & $38(61.3)$ & $13(65.0)$ \\
\hline Progressive disease & $11(17.7)$ & $4(20.0)$ \\
\hline Not evaluable & $3(4.8)^{\mathrm{a}}$ & $1(5.0)^{b}$ \\
\hline Objective response rate $(95 \% \mathrm{Cl}), \%$ & $16.1(8.0-27.7)$ & $\begin{array}{l}10.0(1.2- \\
31.7)\end{array}$ \\
\hline Disease control rate, $\%$ & 77.4 & 75.0 \\
\hline Response duration & $1 \mathrm{~L}(n=10)$ & $2 \mathrm{~L}(n=2)$ \\
\hline $\begin{array}{l}\text { Median duration of response }(95 \% \mathrm{Cl}) \text {, } \\
\text { months }\end{array}$ & 9.9 (2.8-NE) & NE (6.9-NE) \\
\hline \multicolumn{3}{|c|}{ Proportion of patients with specified duration of response $(95 \% \mathrm{Cl}), \%^{\mathrm{c}}$} \\
\hline 6 months & $60.0(25.3-82.7)$ & 100.0 (NE) \\
\hline 12 months & $30.0(7.1-57.8)$ & $\begin{array}{l}50.0(0.6- \\
91.0)\end{array}$ \\
\hline
\end{tabular}

${ }^{a}$ Due to no postbaseline assessment $(n=2)$ or stable disease of insufficient duration ( $<6$ weeks after start date without further tumor assessment; $n=1$ )

${ }^{b}$ All postbaseline assessments not evaluable $(n=1)$

' Based on Kaplan-Meier estimates

$1 L$ first-line subgroup, $2 L$ second-line subgroup, $C l$ confidence interval, $N E$ not evaluable

were assessed every 6 weeks for the first year and every 12 weeks thereafter by investigators according to RECIST v1.1. Safety was assessed at each biweekly visit, and AEs were graded according to the National Cancer Institute's Common Terminology Criteria for Adverse Events (NCICTCAE), v4.0. Immune-related AEs (irAEs) were identified using a prespecified list of Medical Dictionary for Regulatory Activities (MedDRA) preferred terms, followed by comprehensive medical review. Infusion-related reactions (IRRs) were identified using an expanded definition that included both a prespecified list of MedDRA preferred terms (IRR, drug hypersensitivity, or hypersensitivity reaction) that occurred after infusion on the same day or following day, and additional signs/symptoms that occurred on the day of infusion and resolved within 2 days. PD-L1 expression was assessed using a proprietary immunohistochemistry assay (PD-L1 IHC 73-10 assay; Dako, Carpinteria, CA). PD-L1+ status was defined as PD-L1 expression on $\geq 1 \%$ of tumor cells.

\section{Endpoints}

Prespecified endpoints included confirmed best overall response according to RECIST v1.1 (investigator assessed), duration of response (DOR), progression-free survival (PFS) according to RECIST v1.1, OS, PD-L1 expression, and safety. 


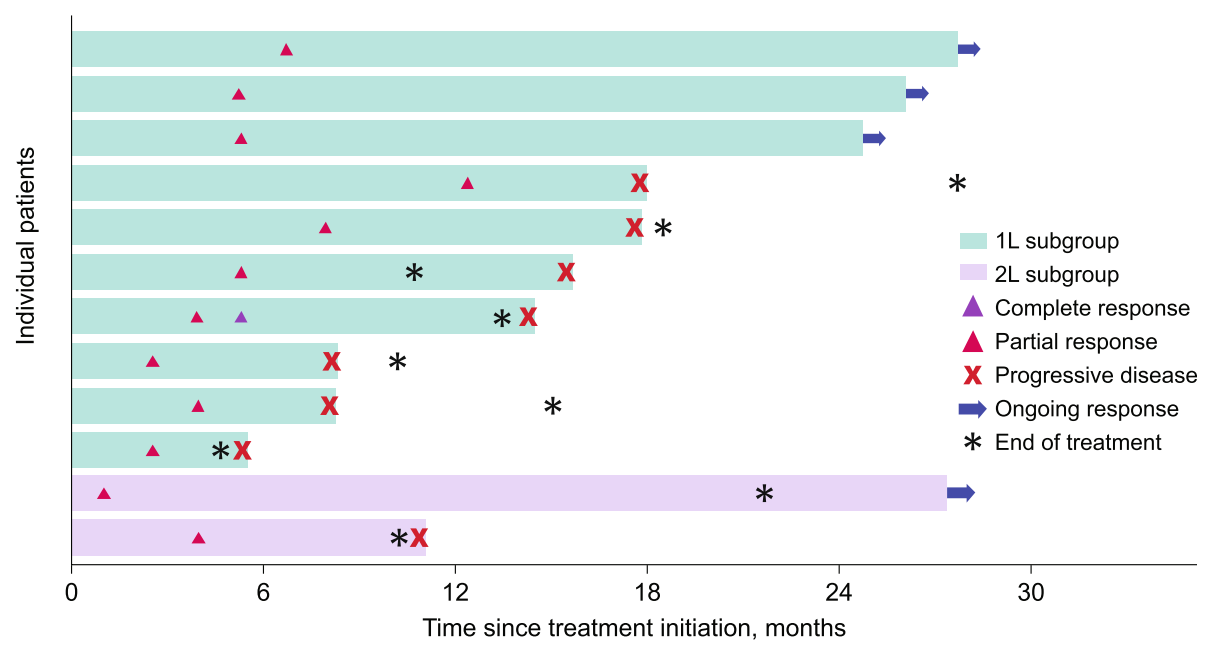

Fig. 1 Time to and duration of confirmed response. 1 L first-line, $2 L$ second-line

\section{Statistical analysis}

Enrolment of the $1 \mathrm{~L}$ subgroup began after documentation of two objective responses in the $2 \mathrm{~L}$ subgroup. Separate analyses of $1 \mathrm{~L}$ and $2 \mathrm{~L}$ subgroups were prespecified. The planned sample size of 20 patients in the $2 \mathrm{~L}$ subgroup was selected to enable observation of at least two responders with a probability of $>89.8 \%$ if the true objective response rate (ORR; proportion of patients with a partial response $[\mathrm{PR}]$ or complete response $[\mathrm{CR}]$ ) was $\geq 18 \%$. The planned sample size of 60 patients in the $1 \mathrm{~L}$ subgroup was selected to provide $95 \%$ Clopper-Pearson confidence intervals (CIs) for an ORR of $20 \%$ (95\% CI, 10.8-32.3) in the case of 12 responders and $25 \%$ (95\% CI, 14.7-37.9) in the case of 15 responders. Time-to-event endpoints were estimated using the Kaplan-Meier method, and CIs for medians were calculated using the Brookmeyer-Crowley method. $P$ values for the association between PD-L1 status and ORR were determined using Fisher exact test.

\section{Results}

\section{Patients and treatment}

Between May 11, 2015, and October 13, 2016, 82 patients were enrolled, comprising 62 in the $1 \mathrm{~L}$ subgroup and 20 in the $2 \mathrm{~L}$ subgroup (Table 1 ). In the $1 \mathrm{~L}$ and $2 \mathrm{~L}$ subgroups, respectively, median age was 62 years (range, 36-85) and 69 years (range, 30-80); 43 (69.4\%) and 15 (75.0\%) patients were male; $25(40.3 \%)$ and 11 (55.0\%) had an ECOG PS of 1; and 20 (32.3\%) and four (20.0\%) had PD-L1+ tumors. At the time of data cutoff (April $27,2018)$, median follow-up in the $1 \mathrm{~L}$ and $2 \mathrm{~L}$ subgroups was 26.2 months (range, 18-29) and 34.1 months (range, 28-35), respectively. Median duration of treatment was 9.6 months (range, 0.9-29.0) in the $1 \mathrm{~L}$ subgroup and 5.3 months (range, $0.9-34.5$ ) in the $2 \mathrm{~L}$ subgroup. At last follow-up, 12 patients (19.4\%) in the 1 L subgroup and two patients (10.0\%) in the $2 \mathrm{~L}$ subgroup remained on treatment. In both subgroups, the most common reason for discontinuation was disease progression ( $1 \mathrm{~L}, n=40$ [64.5\%]; $2 \mathrm{~L}, n=14$ [70.0\%]), and other reasons were $\mathrm{AE}(1 \mathrm{~L}, n=4[6.5 \%] ; 2 \mathrm{~L}, n=3[15 \%])$, withdrawal of consent ( $1 \mathrm{~L}, n=1$ [1.6\%]), death ( $1 \mathrm{~L}, n=$ 1 [1.6\%]; $2 \mathrm{~L}, n=1$ [5.0\%]), and other ( $1 \mathrm{~L}, n=4$ [6.5\%]; two patients required prohibited concomitant medication, one patient met an exclusion criterion, and one patient decided to undergo surgery).

\section{Antitumor activity}

In the $1 \mathrm{~L}$ and $2 \mathrm{~L}$ subgroups, respectively, the ORR was $16.1 \%$ (CR, $n=1$ [1.6\%]; PR, $n=9$ [14.5\%]) and $10.0 \%$ (PR, $n=2$ ) (Table 2; Fig. 1); median DOR was 9.9 months (95\% CI, 2.8-not evaluable) and not evaluable (95\% CI, 6.9-not evaluable); and 38 (61.3\%) and 13 (65.0\%) patients had a best overall response of stable disease, resulting in disease control rates of 77.4 and $75.0 \%$. Median PFS was 8.3 months (95\% CI, 5.5-9.5) in the $1 \mathrm{~L}$ subgroup and 5.6 months (95\% CI, 2.3-9.6) in the $2 \mathrm{~L}$ subgroup (Fig. 2); 6-month and 12-month PFS rates were 56.7 and $30.9 \%$ in the $1 \mathrm{~L}$ subgroup, and 47.4 and $15.8 \%$ in the $2 \mathrm{~L}$ subgroup, respectively. In the $1 \mathrm{~L}$ and $2 \mathrm{~L}$ subgroups, median OS was not evaluable (95\% $\mathrm{CI}$, not evaluable) and 16.9 months (95\% CI, 8.3-not evaluable); 6-month and 12-month OS rates were 88.6 and $83.7 \%$, and 90.0 and $65.0 \%$, in the $1 \mathrm{~L}$ and $2 \mathrm{~L}$ subgroups, respectively.

\section{Biomarker subgroup analysis}

Among evaluable patients in the $1 \mathrm{~L}$ subgroup with PD$\mathrm{L} 1+(n=20)$ or PD-L1- $(n=21)$ tumors, respectively, 


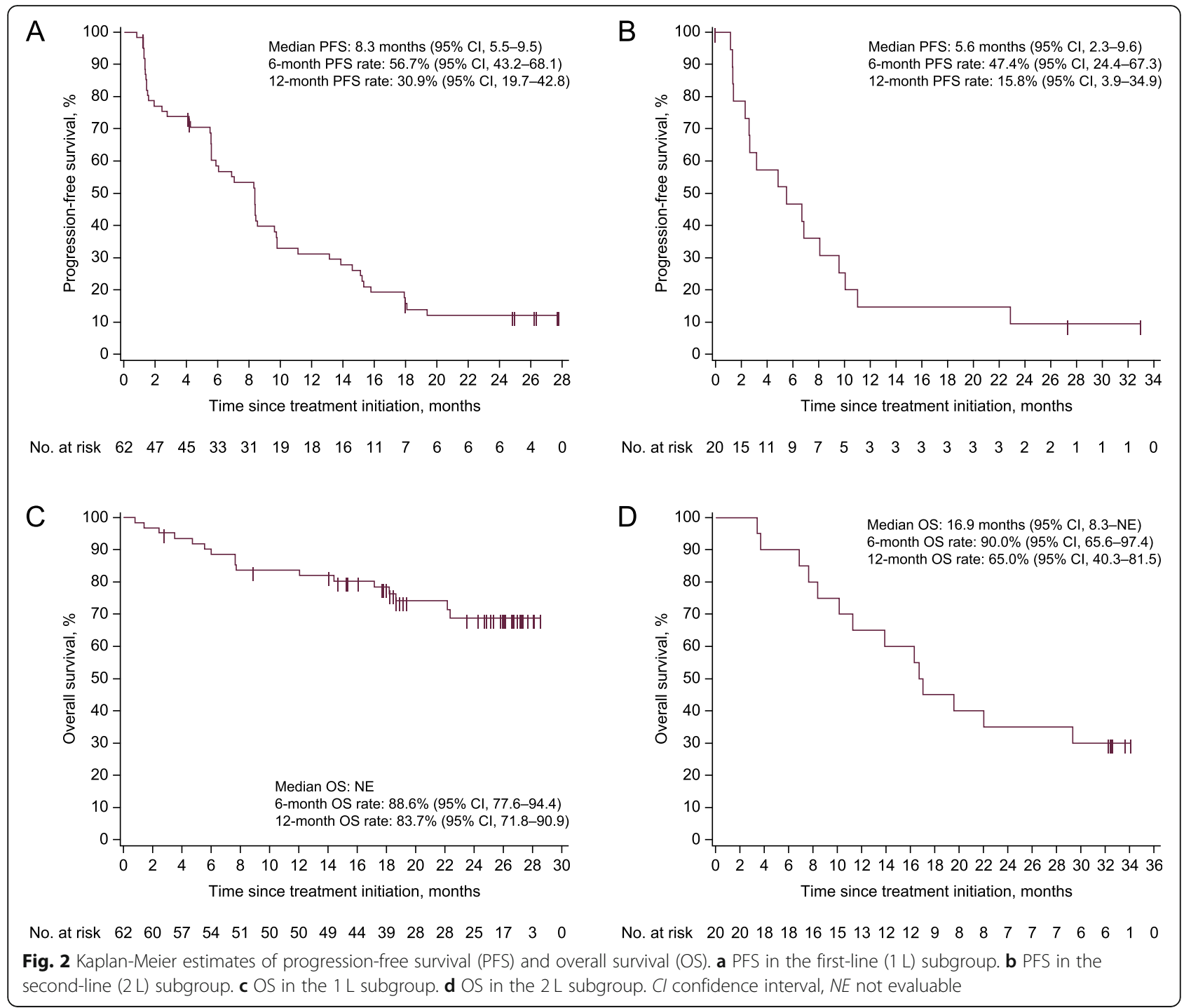

the ORR was $10.0 \%$ (95\% CI, 2.7-24.5) and 14.3\% (95\% CI, 5.4-29.1), median PFS was 5.8 months (95\% CI, 1.9$13.0)$ and 8.3 months (95\% CI, 5.5-15.1), 6-month PFS rates were $48.5 \%(95 \% \mathrm{CI}, 25.4-68.2)$ and $66.7 \%(95 \%$ CI, 42.5-82.5), median OS was not evaluable in either group, and 12-month OS rates were $85.0 \%$ (95\% CI, 60.4-94.9) and 90.5\% (95\% CI, 67.0-97.5) (Additional file 1). Results from the $2 \mathrm{~L}$ subgroup are not reported owing to low patient numbers.

\section{Safety}

Of patients in the $1 \mathrm{~L}$ and $2 \mathrm{~L}$ subgroups, 51 (82.3\%) and $14(70.0 \%)$ had a treatment-related AE (TRAE) of any grade, including eight (12.9\%) and one (5.0\%) who had a grade $\geq 3$ TRAE, respectively (Table 3; Additional file 2). The only grade $\geq 3$ TRAE that occurred in more than one patient was increased lipase $(1 \mathrm{~L}, n=4[6.5 \%])$.
TRAEs led to discontinuation in three patients $(4.8 \%)$ in the $1 \mathrm{~L}$ subgroup (anaphylactic reaction, aspartate aminotransferase increase, and nephritis) and two patients (10.0\%) in the $2 \mathrm{~L}$ subgroup (IRR and pneumonitis). IRRs (based on an expanded definition) occurred in 22 patients $(35.5 \%)$ in the $1 \mathrm{~L}$ subgroup and six patients (30.0\%) in the $2 \mathrm{~L}$ subgroup; all were grade 1 or 2 . Of patients in the $1 \mathrm{~L}$ and $2 \mathrm{~L}$ subgroups, 18 (29.0\%) and three $(15.0 \%)$ had an irAE of any grade, respectively. The most commonly occurring irAEs ( $\geq 10 \%$ in either subgroup) were thyroid disorders ( $1 \mathrm{~L}, n=10[16.1 \%] ; 2 \mathrm{~L}, n=2$ [10.0\%] and immune-related rash $(1 \mathrm{~L}, n=9$ [14.5\%]; $2 \mathrm{~L}$, $n=1[5.0 \%])$. Two patients $(3.2 \%)$ in the $1 \mathrm{~L}$ subgroup had a grade 3 irAE (rash and colitis, both $n=1$ ); no patients in the $2 \mathrm{~L}$ subgroup had a grade 3 irAE. No grade 4 irAEs occurred in either subgroup. In the $1 \mathrm{~L}$ and $2 \mathrm{~L}$ subgroups, respectively, fourteen patients $(22.6 \%)$ and 
Table 3 Incidence of treatment-related adverse events (TRAEs), infusion-related reactions (IRRs), and immune-related adverse events (irAEs)

\begin{tabular}{|c|c|c|c|c|}
\hline & $1 \mathrm{~L}(n=62)$ & & $2 \mathrm{~L}(n=20)$ & \\
\hline & Any Grade & Grade $\geq 3$ & Any Grade & Grade $\geq 3$ \\
\hline Any TRAE, $n(\%)^{a, b}$ & $51(82.3)$ & $8(12.9)$ & $14(70.0)$ & $1(5.0)$ \\
\hline Pruritus & $12(19.4)$ & 0 & 0 & 0 \\
\hline Fatigue & $11(17.7)$ & 0 & $5(25.0)$ & $1(5.0)$ \\
\hline Asthenia & $9(14.5)$ & 0 & $1(5.0)$ & 0 \\
\hline Nausea & $9(14.5)$ & 0 & 0 & 0 \\
\hline Diarrhea & $8(12.9)$ & 0 & $3(15.0)$ & 0 \\
\hline Pyrexia & $8(12.9)$ & 0 & $2(10.0)$ & 0 \\
\hline Decreased appetite & $6(9.7)$ & 0 & $2(10.0)$ & 0 \\
\hline Increased lipase & $6(9.7)$ & $4(6.5)$ & $1(5.0)$ & 0 \\
\hline Rash & $6(9.7)$ & $1(1.6)$ & 0 & 0 \\
\hline Pneumonitis & $2(3.2)$ & 0 & $2(10.0)$ & 0 \\
\hline Anaphylactic reaction & $1(1.6)$ & $1(1.6)$ & 0 & 0 \\
\hline Colitis & $1(1.6)$ & $1(1.6)$ & 0 & 0 \\
\hline Thrombocytopenia & $1(1.6)$ & $1(1.6)$ & 0 & 0 \\
\hline Infusion-related reactions, $n(\%)^{c, d}$ & $22(35.5)$ & 0 & $6(30.0)$ & 0 \\
\hline Any immune-related $A E, n(\%)^{c}$ & $18(29.0)$ & $2(3.2)$ & $3(15.0)$ & 0 \\
\hline Hypothyroidism & $7(11.3)$ & 0 & $1(5.0)$ & 0 \\
\hline Rash & $5(8.1)$ & $1(1.6)$ & 0 & 0 \\
\hline Hyperthyroidism & $3(4.8)$ & 0 & 0 & 0 \\
\hline Pruritus & $3(4.8)$ & 0 & 0 & 0 \\
\hline Blood TSH increased & $2(3.2)$ & 0 & $1(5.0)$ & 0 \\
\hline Colitis & $1(1.6)$ & $1(1.6)$ & 0 & 0 \\
\hline Diarrhea & $1(1.6)$ & 0 & 0 & 0 \\
\hline Erythema & $1(1.6)$ & 0 & 0 & 0 \\
\hline Nephritis & $1(1.6)$ & 0 & 0 & 0 \\
\hline Pruritus generalized & $1(1.6)$ & 0 & 0 & 0 \\
\hline Psoriasis & $1(1.6)$ & 0 & 0 & 0 \\
\hline Rash generalized & $1(1.6)$ & 0 & 0 & 0 \\
\hline Rash macular & $1(1.6)$ & 0 & 0 & 0 \\
\hline Pneumonitis & 0 & 0 & $1(5.0)$ & 0 \\
\hline Rash pruritic & 0 & 0 & $1(5.0)$ & 0 \\
\hline
\end{tabular}

a The incidence of treatment-related infusion-related reactions based on the single MedDRA preferred term is not listed

${ }^{b}$ Any grade TRAEs in $\geq 10 \%$ patents and all grade 3 TRAEs

c Composite term; includes AEs categorized as infusion-related reaction, drug hypersensitivity, or hypersensitivity reaction that occurred on the day of infusion or day after infusion, in addition to signs/symptoms of infusion-related reaction (based on a prespecified list of MedDRA preferred terms) that occurred on the same day of infusion and resolved within 2 days

d Includes AEs classified by investigators as related or unrelated to treatment

$1 L$ first-line subgroup, $2 L$ second-line subgroup, $A E$ adverse event, MedDRA Medical Dictionary for Regulatory Activities, TRAE treatment-related adverse events, TSH thyroid-stimulating hormone

seven patients (35.0\%) had serious AEs, which were related to treatment in two patients $(3.2 \%)$ in the $1 \mathrm{~L}$ subgroup (grade 3 colitis and grade 2 hyperthermia, both $n=1)$. Four patients $(6.5 \%)$ in the $1 \mathrm{~L}$ subgroup and two patients $(10.0 \%)$ in the $2 \mathrm{~L}$ subgroup had an $\mathrm{AE}$ leading to death (none treatment related).

\section{Discussion}

In this phase Ib study, avelumab monotherapy showed clinical activity as a $1 \mathrm{~L}$ or $2 \mathrm{~L}$ treatment for patients with mRCC. Responses were durable (median DOR was 9.9 months $[1 \mathrm{~L}]$ and not evaluable $[2 \mathrm{~L}])$, and disease control rates were high in both subgroups $(1 \mathrm{~L}, 77.4 \%$; 2 
L, 75.0\%). Median PFS was 8.3 months in the $1 \mathrm{~L}$ subgroup and 5.6 months in the $2 \mathrm{~L}$ subgroup, and 12month OS rates were $83.7 \%$ ( $1 \mathrm{~L}$; median, not evaluable) and $65.0 \%$ ( $2 \mathrm{~L}$; median, 16.9 months). Responses to avelumab occurred irrespective of PD-L1 status, and no significant survival difference was seen between PD-L1+ and PD-L1- populations. Avelumab showed an acceptable safety profile, including a low rate of grade $3 / 4$ TRAEs $(12.9$ and $5.0 \%$ in the $1 \mathrm{~L}$ and $2 \mathrm{~L}$ subgroups, respectively). These results are comparable with those reported with TKI monotherapy [7].

Results of this study were generally consistent with those in previous studies of anti-PD-1/PD-L1 monotherapy administered as either $1 \mathrm{~L}$ or $2 \mathrm{~L}$ treatment for mRCC. In the nivolumab monotherapy arm of the phase III CheckMate 025 study (patients with previously treated advanced clear-cell RCC $[n=410])$, median PFS was 4.6 months (95\% CI, 3.7-5.4), median OS was 25 months (95\% CI, 21.8-not evaluable), the ORR was $25 \%$, and $19 \%$ of patients had a grade $3 / 4$ TRAE [13]. In the atezolizumab monotherapy arm of the randomized, phase II IMmotion150 study of patients with treatmentnaive mRCC $(n=103)$, median PFS was 6.1 months (95\% CI, 5.4-13.6), OS was not reported, the ORR was $25 \%$ (CR, 11\%; PR, 14\%), and $17 \%$ of patients had a grade 3/4 TRAE [28]. Finally, in cohort A of the phase II KEYNOTE-427 study, which enrolled patients with advanced clear-cell RCC $(n=110), 1 \mathrm{~L}$ pembrolizumab monotherapy resulted in a median PFS of 6.9 months (95\% CI, 5.1-not evaluable), 6-month OS rate of $92.4 \%$ (median, not reached), and ORR of 33.6\% (95\% CI, 24.843.4), and $18.2 \%$ of patients had a grade $3-5$ TRAE [29].

Preliminary findings from this study supported the rationale for the JAVELIN Renal 100 study (phase Ib avelumab in combination with axitinib $[n=55]$ ) [25], and the recently reported JAVELIN Renal 101 trial, a randomized phase III study of avelumab plus axitinib ( $n=$ 442) compared with sunitinib $(n=444)$ as $1 \mathrm{~L}$ treatment for patients with advanced clear-cell RCC. Median PFS in patients with PD-L1+ tumors (primary endpoint) was 13.8 vs 7.2 months, respectively (hazard ratio, 0.61 [95\% CI, 0.47-0.79]; $P<0.001$ ); in all patients (irrespective of PD-L1 expression), median PFS was 13.8 vs 8.4 months (hazard ratio, 0.69 [95\% CI, 0.56-0.84]; $P<0.001$ ), and the ORR was $51.4 \%$ vs $25.7 \%$, respectively [26]. The enhanced efficacy of the combination may result from synergistic antitumor effects provided by the different mechanisms of action of avelumab and axitinib, including the known immunomodulatory effects of vascular endothelial growth factor receptor tyrosine kinase inhibitors $[25,26]$. Improved efficacy with anti-PD-1/PD-L1 combinations in the $1 \mathrm{~L}$ setting have also been reported for pembrolizumab plus axitinib (KEYNOTE-426) [24], nivolumab plus ipilimumab (CheckMate 214) [14], and atezolizumab plus bevacizumab (IMmotion151) [30], highlighting the rapidly evolving treatment landscape in advanced RCC.

\section{Conclusion}

In conclusion, results from this study show the efficacy and safety of avelumab in patients with mRCC, supporting the foundational role of ICIs within combination treatment regimens for this disease.

\section{Supplementary information}

Supplementary information accompanies this paper at https://doi.org/10. 1186/s40425-019-0746-2.

Additional file 1 Kaplan-Meier estimates of a progression-free survival (PFS) and $\mathbf{b}$ overall survival (OS) in the first-line subgroup according to programmed death-ligand 1 (PD-L1) status (based on expression in $\geq 1 \%$ of tumor cells). Cl confidence interval, NE not evaluable. Kaplan-Meier estimates of progression-free survival and overall survival for patients in the first-line subgroup according to programmed death-ligand 1 status.

Additional file 2. Overview of key safety outcomes. Key safety outcomes for patients in both the first-line and second-line treatment setting.

\section{Abbreviations}

1 L: First-line; 2 L: Second-line; AE: Adverse event; Cl: Confidence interval; CR: Complete response; DOR: Duration of response; ECOG PS: Eastern Cooperative Oncology Group performance score; ICl: Immune-checkpoint inhibitor; irAE: Immune-related adverse event; IRR: Infusion-related reaction; MedDRA: Medical Dictionary for Regulatory Activities; mRCC: Metastatic renal cell carcinoma; NCI-CTCAE: National Cancer Institute Common Terminology Criteria for Adverse Events; ORR: Objective response rate; OS: Overall survival; PD-1: Programmed death-1; PD-L1: Programmed death-ligand 1; PFS: Progression-free survival; PR: Partial response; RCC: Renal cell carcinoma; RECIST: Response Evaluation Criteria In Solid Tumors; TKI: Tyrosine kinase inhibitor; TRAE: Treatment-related adverse event

\section{Acknowledgements}

The authors thank the patients and their families, investigators, coinvestigators, and study teams at each of the participating centres and at Merck KGaA, Darmstadt, Germany, and EMD Serono, Billerica, MA, USA (a business of Merck KGaA, Darmstadt, Germany).

\section{Authors' contributions}

Provision of study materials or patients: UV, PS, AR, CB, JP, JC, JCM, NK, MS, JLG. Collection and assembly of data: all authors. Data analysis and interpretation: all authors. Manuscript writing: all authors. Final approval of manuscript: all authors. Accountable for all aspects of the work: all authors.

\section{Funding}

This work was supported by Merck KGaA, Darmstadt, Germany, and is part of an alliance between Merck KGaA and Pfizer, Inc., New York, NY, USA. Medical writing support was provided by ClinicalThinking and funded by Merck KGaA, and Pfizer, Inc.

\section{Availability of data and materials}

For all new products or new indications approved in both the European Union and the United States after January 1, 2014, Merck KGaA, Darmstadt, Germany will share patient-level and study-level data after deidentification, as well as redacted study protocols and clinical study reports from clinical trials in patients. These data will be shared with qualified scientific and medical researchers, upon researcher's request, as necessary for conducting legitimate research. Such requests must be submitted in writing to the company's data sharing portal. More information can be found at https://www.merckgroup. com/en/research/our-approach-to-research-and-development/healthcare/ clinical-trials/commitment-responsible-data-sharing.html. Where Merck KGaA 
has a co-research, co-development or co-marketing/co-promotion agreement or where the product has been out-licensed, it is recognized that the responsibility for disclosure may be dependent on the agreement between parties. Under these circumstances, Merck KGaA will endeavor to gain agreement to share data in response to requests.

\section{Ethics approval and consent to participate}

The trial was conducted in accordance with the Declaration of Helsinki and the International Council for Harmonisation Guideline for Good Clinical Practice. The protocol was approved by the institutional review board or independent ethics committee of each centre, and all patients provided written informed consent before enrolment.

\section{Consent for publication}

Not applicable.

\section{Competing interests}

UV reports research funding from Novartis, Exelixis, and Pfizer; consultancy remuneration from Bayer, Exelixis, Pfizer, Bristol-Myers Squibb, and EMD Serono; and honoraria from Sanofi, Pfizer, Bristol-Myers Squibb, Bayer, and Exelixis. PS reports consultancy or advisory remuneration from Blueprint Medicines, Eisai, Ellipses Pharma, Eli Lilly, Loxo Oncology, Deciphera Pharmaceuticals, Merck KGaA, Servier, Genmab, Adaptimmune, Intellisphere, Transgene, and Plexxikon, and research funding from Blueprint Medicines, Boehringer Ingelheim, CoBioRes NV, Eisai, Exelixis, G1 Therapeutics, Eli Lilly, Novartis, PharmaMar, and Plexxikon. AR reports honoraria and travel expenses from Bristol-Myers Squibb, Novartis, Ipsen, Astra Zeneca, and Pfizer; and consultancy or advisory remuneration from Bristol-Myers Squibb, Ipsen, Novartis, Pfizer, Astra Zeneca, and Roche. JCM reports speakers bureau services for Boehringer Ingelheim and Merck KGaA; travel expenses from Amgen, Eisai, Merck KGaA, and VentiRx Pharmaceuticals; and other relationship with Merck KGaA. MS reports research funding from Merrimack. DZ reports employment with and research funding from Merck KGaA. SG and MB report employment with Merck KGaA. JLG reports research funding from Astellas and Medivation, Bavarian Nordic, Merck KGaA, NantBioScience, and Pfizer. All remaining authors have declared no competing interests.

\section{Author details}

${ }^{1}$ Karmanos Cancer Institute, Wayne State University, 4100 John R. Street

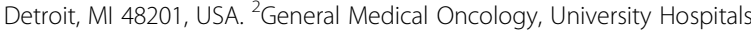
Leuven, Leuven Cancer Institute, Leuven, Belgium. ${ }^{3}$ Medical Oncology, Bordeaux University Hospital, Bordeaux, France. ${ }^{4}$ Medical Oncology, Centre Paul Strauss, Centre de Recherche, Centres de Lutte Contre le Cancer (CRLCC), Strasbourg, France. ${ }^{5}$ Oncology Haematology, Oncology Consultants, Houston, USA. ${ }^{6}$ Haematology-Oncology, Northwest Medical Specialties, Lakewood, USA. ${ }^{7}$ Internal Medicine, University of Cincinnati, Cincinnati, USA. ${ }^{8}$ Centre Oscar Lambret, Lille, France. ${ }^{9}$ Horovice Oncology Clinic, Nemocnice Rudolfa a Stefanie Benešov, a. s, Benešov, Czech Republic. ${ }^{10}$ Merck Serono Pharmaceutical R\&D Co, Beijing, China. ${ }^{11}$ Merck KGaA, Darmstadt, Germany. ${ }^{12}$ Global Clinical Development, EMD Serono, Billerica, USA. ${ }^{13}$ Genitourinary Malignancies Branch, Center for Cancer Research, National Cancer Institute, National Institutes of Health, Bethesda, USA.

Received: 31 May 2019 Accepted: 20 September 2019 Published online: 24 October 2019

\section{References}

1. American Cancer Society. What is kidney cancer? 2017. https://www.cancer. org/cancer/kidney-cancer/about/what-is-kidney-cancer.html. Accessed 04 March 2019

2. Surveillance, Epidemiology, And end results program. Cancer Stat Facts: kidney and renal pelvis cancer https://seer.cancer.gov/statfacts/html/kidrp. html. Accessed 04 March 2019

3. Penticuff JC, Kyprianou N. Therapeutic challenges in renal cell carcinoma. Am J Clin Exp Urol. 2015;3(2):77-90

4. Blanco Al, Teh BS, Amato RJ. Role of radiation therapy in the management of renal cell cancer. Cancers (Basel). 2011;3(4):4010-23.

5. Choueiri TK, Motzer RJ. Systemic therapy for metastatic renal-cell carcinoma. N Engl J Med. 2017;376(4):354-66.

6. Hutson TE. Targeted therapies for the treatment of metastatic renal cell carcinoma: clinical evidence. Oncologist. 2011;16(Suppl 2):14-22.
7. Thomas JS, Kabbinavar F. Metastatic clear cell renal cell carcinoma: a review of current therapies and novel immunotherapies. Crit Rev Oncol Hematol. 2015;96(3):527-33.

8. Ross K, Jones RJ. Immune checkpoint inhibitors in renal cell carcinoma. Clin Sci (Lond). 2017;131(21):2627-42.

9. Webb ES, Liu P, Baleeiro R, Lemoine NR, Yuan M, Wang Y. Immune checkpoint inhibitors in cancer therapy. J Biomed Res. 2018;32(5):317-26.

10. lacovelli R, Nolè F, Verri E, Renne G, Paglino C, Santoni M, et al. Prognostic role of PD-L1 expression in renal cell carcinoma: a systematic review and meta-analysis. Target Oncol. 2016;11(2):143-8.

11. Wang Z, Peng S, Xie H, Guo L, Cai Q, Shang Z, et al. Prognostic and clinicopathological significance of PD-L1 in patients with renal cell carcinoma: a meta-analysis based on 1863 individuals. Clin Exp Med. 2018; 18(2):165-75.

12. Thompson $\mathrm{RH}$, Dong $\mathrm{H}$, Kwon ED. Implications of B7-H1 expression in clear cell carcinoma of the kidney for prognostication and therapy. Clin Cancer Res. 2007;13(2):709s-15s.

13. Motzer RJ, Escudier B, McDermott DF, George S, Hammers HJ, Srinivas S, et al. Nivolumab versus everolimus in advanced renal cell carcinoma. N Engl J Med. 2015;373(19):1803-13.

14. Motzer RJ, Tannir NM, McDermott DF, Frontera OS, Melichar B, Choueiri TK, et al. Nivolumab plus ipilimumab versus sunitinib in advanced renal-cell carcinoma. N Engl J Med. 2018;378(14):1277-90.

15. Heery CR, O'Sullivan-Coyne G, Madan RA, Cordes L, Rajan A, Rauckhorst M et al. Avelumab for metastatic or locally advanced previously treated solid tumours (JAVELIN Solid Tumor): a phase 1a, multicohort, dose-escalation trial. Lancet Oncol. 2017;18(5):587-98.

16. Bavencio (avelumab) [package insert]. Rockland, MA: EMD Serono; 2019. https://www.accessdata.fda.gov/drugsatfda_docs/label/2017/761049s000lbl. pdf. Accessed 14 May 2019.

17. Gulley JL, Rajan A, Spigel DR, lannotti N, Chandler J, Wong DJL, et al. Avelumab for patients with previously treated metastatic or recurrent non-small-cell lung cancer (JAVELIN Solid Tumor): dose-expansion cohort of a multicentre, open-label, phase 1b trial. Lancet Oncol. 2017; 18(5):599-610.

18. Disis ML, Taylor MH, Kelly K, Beck JT, Gordon M, Moore KM, et al. Efficacy and safety of avelumab for patients with recurrent or refractory ovarian cancer: phase $1 \mathrm{~b}$ results from the JAVELIN Solid Tumor trial. JAMA Oncol. 2019;5(3):393-401.

19. Patel MR, Ellerton J, Infante JR, Agrawal M, Gordon M, Aljumaily R, et al. Avelumab in metastatic urothelial carcinoma after platinum failure (JAVELIN Solid Tumor): pooled results from two expansion cohorts of an open-label, phase 1 trial. Lancet Oncol. 2018;19(1):51-64.

20. Hassan R, Thomas A, Nemunaitis JJ, Patel MR, Bennouna J, Chen FL, et al. Efficacy and safety of avelumab treatment in patients with advanced unresectable mesothelioma: phase $1 \mathrm{~b}$ results from the JAVELIN Solid Tumor trial. JAMA Oncol. 2019;5(3):351-7.

21. Chung HC, Arkenau H-T, Lee J, Rha SY, Oh D-Y, Wyrwicz L, et al. Avelumab (anti-PD-L1) as first-line switch-maintenance or second-line therapy in patients with advanced gastric or gastroesophageal junction cancer: phase $1 \mathrm{~b}$ results from the JAVELIN Solid Tumor trial. J Immunother Cancer. 2019;7(1):30.

22. Le Tourneau C, Hoimes C, Zarwan C, Wong DJ, Bauer S, Claus R, et al. Avelumab in patients with previously treated metastatic adrenocortical carcinoma: phase $1 \mathrm{~b}$ results from the JAVELIN Solid Tumor trial. J Immunother Cancer. 2018;6(1):111.

23. Keilholz U, Mehnert JM, Bauer S, Bourgeois H, Patel MR, Gravenor D, et al. Avelumab in patients with previously treated metastatic melanoma: phase 1b results from the JAVELIN Solid Tumor trial. J Immunother Cancer. 2019; 7(1):12.

24. Rini Bl, Plimack ER, Stus V, Gafanov R, Hawkins R, Nosov D, et al. Pembrolizumab plus axitinib versus sunitinib for advanced renal-cell carcinoma. N Engl J Med. 2019;380(12):1116-27.

25. Choueiri TK, Larkin J, Oya M, Thistlethwaite F, Martignoni M, Nathan P, et al. Preliminary results for avelumab plus axitinib as first-line therapy in patients with advanced clear-cell renal-cell carcinoma (JAVELIN renal 100): an openlabel, dose-finding and dose-expansion, phase 1b trial. Lancet Oncol. 2018; 19(4):451-60.

26. Motzer RJ, Penkov K, Haanen J, Rini B, Albiges L, Campbell MT, et al. Avelumab plus axitinib versus sunitinib for advanced renal-cell carcinoma. N Engl J Med. 2019;380(12):1103-15. 
27. Atkins MB, Plimack ER, Puzanov I, Fishman MN, McDermott DF, Cho DC, et al. Axitinib in combination with pembrolizumab in patients with advanced renal cell cancer: a non-randomised, open-label, dose-finding, and dose-expansion phase 1b trial. Lancet Oncol. 2018 Mar;19(3):405-15.

28. McDermott DF, Huseni MA, Atkins MB, Motzer RJ, Rini BI, Escudier B, et al. Clinical activity and molecular correlates of response to atezolizumab alone or in combination with bevacizumab versus sunitinib in renal cell carcinoma. Nat Med. 2018;24(6):749-57.

29. Donskov F, McDermott DF, Lee JL, Szczylik C, Malik J, Alekseev BY, et al. KEYNOTE-427 cohort A: pembrolizumab monotherapy as first-line therapy in advanced clear cell renal cell carcinoma (ccRCC). Ann Oncol. 2018;29(Suppl 8):viii303-31.

30. Rini Bl, Powles T, Atkins MB, Escudier B, McDermott DF, Suarez C, et al. Atezolizumab plus bevacizumab versus sunitinib in patients with previously untreated metastatic renal cell carcinoma (IMmotion151): a multicentre, open-label, phase 3, randomised controlled trial. Lancet Oncol. 2019;19(1): $51-64$.

\section{Publisher's Note}

Springer Nature remains neutral with regard to jurisdictional claims in published maps and institutional affiliations.

Ready to submit your research? Choose BMC and benefit from:

- fast, convenient online submission

- thorough peer review by experienced researchers in your field

- rapid publication on acceptance

- support for research data, including large and complex data types

- gold Open Access which fosters wider collaboration and increased citations

- maximum visibility for your research: over $100 \mathrm{M}$ website views per year

At $\mathrm{BMC}$, research is always in progress.

Learn more biomedcentral.com/submissions 